\title{
Pré-resfriamento em água de lichia ‘B3’ mantida em armazenamento refrigerado
}

\author{
Hydrocooling of 'B3' lychee fruit maintained in cold storage
}

\author{
Juan Saavedra del Aguila ${ }^{\mathrm{I}}$ Peter Hofman ${ }^{\text {II }}$ Terrence Campbell ${ }^{I I}$ \\ José Roberto Marques ${ }^{\text {II }}$ Lília Sichmann Heiffig - del Aguila ${ }^{\text {III }}$ Ricardo Alfredo Kluge $^{\text {IV }}$
}

RESUMO

Este experimento visou a estudar o efeito de diferentes temperaturas e tempos de pré-resfriamento em água sobre a qualidade de lichias 'B3', após a frigoconservação. Os tratamentos foram: $T 1$ = controle (sem pré-resfriamento); $T 2=$ imersão por cinco minutos em água a $2,5^{\circ} \mathrm{C} ; \mathrm{T} 3=$ imersão por 10 minutos em água a 2,5 ${ }^{\circ} \mathrm{C}$; T4 = imersão por 20 minutos em água a 2,5 $5^{\circ}$; $T 5=$ imersão por sete minutos em água a $6^{\circ} \mathrm{C}$; T6 = imersão por 20 minutos em água a $8^{\circ} \mathrm{C}$ e $\mathrm{T7}=$ imersão por 10 minutos em água a $10^{\circ} \mathrm{C}$. Após a aplicação dos respectivos tratamentos, os frutos foram acondicionados em filmes de polietileno de $24 \mu \mathrm{m}$, selados e posteriormente armazenados a $5{ }^{\circ} \mathrm{C}$ e $90 \%$ UR, por um periodo de sete dias, seguido por três dias de comercialização simulada a $20^{\circ} \mathrm{C} e$ $70 \%$ UR. O delineamento experimental foi inteiramente ao acaso, com tratamentos fatoriais de $7 \times 3$ (tratamentosxtempo). Foram utilizadas quatro repetições por tratamento, sendo cada uma composta por $150 \mathrm{~g}$ de frutos. Determinaram-se: perda de massa fresca, coloração ( $L^{*}$, a e b), escurecimento (\%) e podridões (\%). De acordo com os resultados, o pré-resfriamento com água reduz a percentagem de escurecimento, o decréscimo da luminosidade $\left(L^{*}\right)$ e os valores de a. Por outro lado, esse tratamento favorece o surgimento de altos índices de podridão.

Palavras-chave: Litchi chinensis Sonn., refrigeração, calor de campo.

\section{ABSTRACT}

This project studied the effects of different precooling temperatures and times with water on lychee ' $B 3$ ' fruit quality cold storage. The treatments were: $T 1=$ control (without precooling); $T 2=$ immersed in water at $2.5^{\circ} \mathrm{C}$ for five minutes; T3 = immersed in water at $2.5^{\circ} \mathrm{C}$ for ten minutes; T4 $=$ immersed in water at $2.5^{\circ} \mathrm{C}$ for 20 minutes; $T 5=$ immersed in water at $6^{\circ} \mathrm{C}$ for seven minutes; T6 = immersed in water at $8^{\circ} \mathrm{C}$ for 20 minutes and $T 7=$ immersed in water at $10^{\circ} \mathrm{C}$ for ten minutes. After treatments application, the fruits were then placed into polyethylene bags of $24 \mu \mathrm{m}$, sealed, and stored for seven days at $5^{\circ} \mathrm{C}$ and $90 \% \mathrm{RH}$, plus 3 days at $20^{\circ} \mathrm{C}$ and $70 \% \mathrm{RH}$ to simulate commercial conditions. Completely randomized experimental design, with factorial $7 \times 3$ (treatments $x$ time). The research used four replicates for treatment, approximately 150g. It was determined: weight loss, color ( $L^{*}, a$ and b), browning (\%) and rots (\%). According to the results, the lychee hydrocooling reduced the browning percentage, the brightness decrease $\left(L^{*}\right)$ and a values. In the other hand, this treatment also resulted in higher percentage of rots.

Key words: Litchi chinensis Sonn., refrigeration, field heat.

\section{INTRODUÇÃO}

A lichia (Litchi chinensis Sonn.) é nativa da região compreendida entre o sul da China e o norte do Vietnã, onde é cultivada há mais de três mil anos. Mais recentemente, está sendo cultivada em alguns países de climas subtropicais. O fruto é muito conhecido e apreciado na Ásia, onde se concentra cerca de $95 \%$ da área mundial da cultura, tendo sido duplicado a sua produção entre os anos de 1999 a 2001, passando de 950.000 toneladas para dois milhões de toneladas de frutos nesse período, comprovando sua importância para milhões de agricultores (MENZEL \& WAITE, 2005). As lichias se deterioram rapidamente, a menos que sejam empregadas técnicas adequadas de

IPrograma de Pós-graduação em Fitotecnia, Escola Superior de Agricultura “Luiz de Queiroz” (ESALQ), Universidade de São Paulo (USP), CP 09, 13418-900, Piracicaba, SP, Brasil. E-mail: jsaguila@esalq.usp.br. Autor para correspondência.

${ }^{I}$ Department of Primary Industries and Fisheries (DPI \& F), Queensland, Austrália.

IIIInstituto Agronômico (IAC), Centro de Grãos e Fibras, Campinas, SP, Brasil.

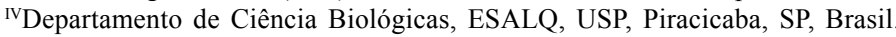


conservação. Os principais fatores que reduzem a vida pós-colheita da lichia são as doenças pós-colheita e o rápido escurecimento do pericarpo.

O pré-resfriamento é a primeira etapa no manejo da temperatura. A maior parte dos ambientes refrigerados não possui capacidade de refrigeração e movimento de ar para um resfriamento rápido. Consequentemente, o pré-resfriamento é, em geral, uma operação separada, que requer equipamentos e/ou recintos especiais. Essa etapa tem por finalidade a remoção rápida do calor do campo dos produtos recémcolhidos (calor vital e calor do campo), antes do armazenamento, processamento ou transporte para locais distantes. Quando realizado de modo adequado, o pré-resfriamento reduz a incidência de doenças e retarda a perda de frescor e de qualidade, porque inibe o crescimento de microrganismos, restringe as atividades enzimáticas e respiratória, inibe a perda de água e reduz a produção de etileno pelo produto (CHITARRA\& CHITARRA, 2005).

O resfriamento é fortemente afetado pela temperatura inicial do produto e esta pelo horário e condições no momento da colheita e pelo tempo de espera antes do resfriamento. Muitas vezes, o produto é colhido pela manhã, mas se aquece no campo ou no galpão de embalagem, no decorrer do dia (KLUCH et al., 2003). Existem diferentes métodos de resfriamento rápido, como, por exemplo: resfriamento rápido por ar, com água, com gelo (na embalagem) e pelo vácuo.

No que diz respeito ao método de resfriamento rápido por água fria, tem-se que um filme de água fria flui rápida e uniformemente sobre a superfície do produto, que está mais quente que a água, e a temperatura desta superfície torna-se igual geralmente a $7 / 8$ da temperatura da água. Nesse processo, o produto hortícola é resfriado com água fria por imersão, lavagem ou aspersão (CORTEZ et al., 2002). A maior capacidade da água em extrair calor faz com que esse seja um método muito mais rápido que o resfriamento rápido por ar.

Dentre os produtos hortícolas que são frequentemente resfriados por água fria, podem-se citar: maçã, milho, cenoura, aipo, rabanete, pêssego, cereja, melão e lichia (CORTEZ et al., 2002). Os produtos que podem ser resfriados com água devem ser tolerantes ao contato e aos níveis de cloro na água tratada.

Em lichia, recomendam-se os seguintes métodos de resfriamento rápido: ar forçado a $5^{\circ} \mathrm{C}$ por quatro horas; água fria a $4^{\circ} \mathrm{C}$ por 10 a 20 minutos, sendo este último método o mais usado. Porém, uma vez removido do armazenamento refrigerado e colocado no ambiente, os frutos podem deteriorar-se rapidamente devido ao escurecimento do pericarpo e ao aparecimento de podridões (MENZEL \& WAITE; 2005; JIANG et al., 2006).

Apesar da existência dessas recomendações técnicas de resfriamento rápido de lichia e, especificamente, do método de resfriamento rápido com água fria, não se têm referências precisas na literatura científica das temperaturas internas do fruto (polpa) em função das diferentes temperaturas e tempos de resfriamento rápido com água fria. Esta informação é importante, uma vez que o objetivo do resfriamento rápido é a retirada do calor de campo, o qual poderia ser alcançado em menos tempo de imersão ou variandose a temperatura da água fria, com o que conseguiríamos utilizar somente a energia necessária para esse processo. Além disso, um período excesivo de contato dos frutos com a água fria poderia ocasionar, ao longo do armazenamento ou comercialização, uma maior presença de podridões nos frutos. Para que o processo de pré-resfriamento seja eficaz, este deve ser realizado em tempo mínimo.

Na prática, em função da logística de cada packinghouse, estão sendo utilizadas, pelos produtores de lichia, diferentes temperaturas na água para o resfriamento rápido e tempos variáveis de imersão. Assim sendo, o presente experimento objetivou determinar os efeitos de diferentes temperaturas e tempos de imersão durante o préresfriamento com água sobre a conservação refrigerada de lichia 'B3'.

\section{MATERIAL E MÉTODOS}

O experimento foi desenvolvido no Postharvest Laboratory, Horticulture and Forestry Sciences, pertencente ao Department of Primary Industries and Fisheries (DPI \& F), Maroochy Research Station, na cidade de Nambour, Estado de Queensland, Austrália.

Lichias 'Bosworth 3' ou, como são comumente chamadas, 'B3' ou Kwai May Pink foram adquiridas de um produtor da região de Pomona, Queensland, Austrália, localizada a $26^{\circ} 29^{\prime}$ de latitude Sul, $152^{\circ} 37^{\prime}$ de longitude Oeste e $260 \mathrm{~m}$ de altitude. Imediatamente após a colheita, os frutos foram transportados até o laboratório, onde foram selecionados quanto à firmeza, à ausência de danos mecânicos e às podridões visíveis.

Aplicaram-se os seguintes tratamentos aos frutos: $\mathrm{T} 1=$ controle (retirados diretamente das caixas provenientes de campo); T2=imersão por cinco minutos em água destilada a $2,5^{\circ} \mathrm{C}$ (temperatura da polpa $=7,5^{\circ} \mathrm{C}$ ); $\mathrm{T} 3=$ imersão por 10 minutos em água destilada a $2,5^{\circ} \mathrm{C}$ (temperatura da polpa $=4^{\circ} \mathrm{C}$ ); $\mathrm{T} 4=$ imersão por 20 
minutos em água destilada a $2,5^{\circ} \mathrm{C}$ (temperatura da polpa $\left.=2,8^{\circ} \mathrm{C}\right) ; \mathrm{T} 5=$ imersão por sete minutos em água destilada a $6^{\circ} \mathrm{C}$ (temperatura da polpa $=8,5^{\circ} \mathrm{C}$ ); T6=imersão por 20 minutos em água destilada a $8^{\circ} \mathrm{C}$ (temperatura da polpa $=8,5^{\circ} \mathrm{C}$ ); e, T7=imersão por 10 minutos em água destilada a $10^{\circ} \mathrm{C}$ (temperatura da polpa $=10,6^{\circ} \mathrm{C}$ ).

A temperatura inicial da polpa dos frutos foi de $22^{\circ} \mathrm{C}$. Os tratamentos foram aplicados em máquinas especiais, desenhadas para o pré-resfriamento de lichias com água, contendo $100 \mathrm{ppm}$ de cloro ativo, dentro de uma linha de beneficiamento desses frutos. A temperatura da água utilizada para o pré-resfriamento da polpa foi monitorada por um equipamento contendo uma bateria de 12 termômetros com terminações em forma de agulhas (A.M.S. TECHNICAL SERVICES PTY L.T.D., modelo NEWPORT ${ }^{\circ} \mathrm{C}$ ). Esse equipamento permitiu ter leitura simultânea de todos os termômetros que estavam sendo utilizados ao momento da instalação de cada tratamento.

Após a aplicação dos tratamentos, os frutos foram colocados em filmes de polietileno de $24 \mu \mathrm{m}$, selados, sendo posteriormente armazenados em câmara fria a $5^{\circ} \mathrm{C}\left( \pm 1^{\circ} \mathrm{C}\right)$ e $90 \% \mathrm{UR}( \pm 5 \% \mathrm{UR})$, por um período de sete dias, mais três dias de simulação de comercialização sob condições controladas a $20^{\circ} \mathrm{C}\left( \pm 1^{\circ} \mathrm{C}\right)$ e $70 \%$ UR $( \pm 5 \%$ UR). As avaliações ocorreram no momento de instalação do experimento (dia 0 ), ao final do período de armazenamento refrigerado a $5^{\circ} \mathrm{C}$ (sétimo dia) e ao final da simulação de comercialização a $20^{\circ} \mathrm{C}$ (décimo dia).

O delineamento experimental foi inteiramente ao acaso, com um fatorial $7 \times 3$ (sete tratamentos e três períodos de armazenamento, incluindo o tempo zero). Foram utilizadas quatro repetições, constando cada uma de $150 \mathrm{~g}$ de fruto por tratamento.

As variáveis observadas foram perda de massa fresca (por diferença, em \%, entre a massa inicial e final da repetição) e coloração, para a qual foi utilizado um colorímetro marca Minolta, com iluminante D65, determinando-se os valores de $\mathrm{L}^{*}, a$ e $b$. As leituras foram realizadas diretamente sobre o pericarpo dos frutos. Para a percentagem de escurecimento, utilizouse a escala $\mathrm{a}=<10 \%$ (percentagem de frutos de cada repetição, que apresentavam $<10 \%$ de escurecimento do seu pericarpo), $b=10-25 \%, c=25-50 \%, d=50-75 \%$ e $\mathrm{e}=75-100 \%$. A percentagem de podridões foi obtida por observação visual, determinando-se o número de frutos afetados por podridões visíveis, sendo os resultados expressos em $\%$.

Os resultados obtidos foram analisados pelo programa SAS Institute (1998), sendo submetidos à análise de variância (teste F) e à comparação de médias pelo teste de Tukey a 5\% de probabilidade de erro.

\section{RESULTADOS E DISCUSSÃO}

Os frutos tiveram, em média, perda de massa fresca de 1,1\%, ao longo do experimento (Figura 1), o que se encontra dentro de valores aceitáveis de perda de massa fresca na pós-colheita de vegetais ao longo do armazenamento refrigerado e posterior período de comercialização (SAAVEDRADELAGUILA, 2009).

As podridões variaram entre 18 e $31 \%$ (Figura 2), dependendo do tratamento. As percentagens obtidas neste experimento foram superiores à percentagem máxima de podridões consideradas como limite dentro da comercialização desse fruto, no mercado varejista da Austrália, que é ao redor de $10 \%$, local onde se realizou o presente experimento. Esses resultados indicam a necessidade de pesquisas na área de controle das podridões na pós-colheita de lichia, sendo que, atualmente, não existe nenhum produto comercial registrado no Brasil ou na Austrália que seja utilizado para controlar doenças na pós-colheita desses frutos.

Percentagens de podridões de $12,8 \%$ foram observadas por JIANG et al. (2006) em lichias préresfriadas com água e armazenadas a $5^{\circ} \mathrm{C}$ por 20 dias. Tais resultados, inferiores aos obtidos no presente experimento, devem-se aos frutos terem sido imediatamente avaliados na saída da câmara fria. Resultados similares já haviam sido observados por HOLCROFT \& MITCHAN (1996), quanto ao rápido desenvolvimento de podridões em lichia tratada com pré-resfriamento com água fria e armazenada a baixa temperatura, quando colocada à temperatura ambiente, por BRACKMANN et al. (1996), em maçãs cvs. 'Golden Delicius' e 'Fuji', e por KLUCH et al. (2003), em pêssego cv. 'Chiripá', quando o pré-resfriamento em água aumentou a incidência de podridões em frutos de ambas as espécies.

De outra forma, o resfriamento rápido em água de pêssegos das cvs. 'Chimarrita' e 'Chiripá' é uma prática possível de uso comercial porque retira rapidamente o calor de campo dos frutos e não implica maior ocorrência de podridões durante a armazenagem dos pêssegos, mas favorece maiores perdas de massa (SEIBERT et al., 2007).

$\mathrm{Na}$ figura 3, são apresentadas as percentagens de escurecimento do pericarpo dos frutos, ao início do experimento, na saída da câmara fria $\left(5^{\circ} \mathrm{C}\right)$ e na saída da câmara (simulação de comercialização a $20^{\circ} \mathrm{C}$ ). Observa-se a excelente qualidade desses frutos, ao apresentarem faixas de percentagens de escurecimento muito baixas ao início do experimento (dia 0 ). 


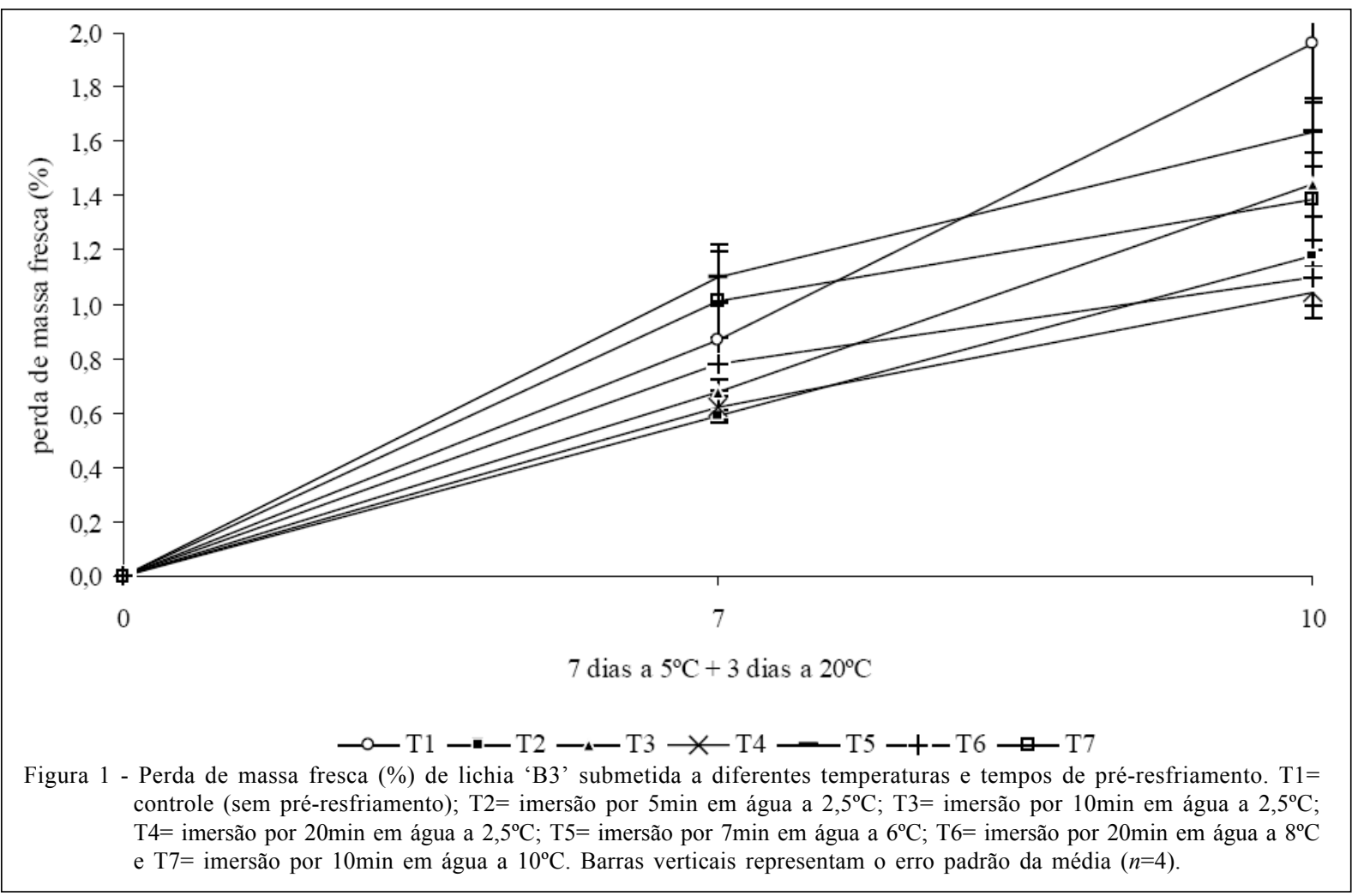

Ao sétimo dia de experimentação, na saída dos frutos do armazenamento refrigerado, houve avanço do escurecimento do pericarpo dos frutos, sendo que, nesse dia, os tratamentos correspondentes a T4, T5, T6 e T7 (imersão por 20 min em água a $2,5^{\circ} \mathrm{C}$; imersão por $7 \mathrm{~min}$ em água a $6^{\circ} \mathrm{C}$; imersão por $20 \mathrm{~min}$ em água a $8^{\circ} \mathrm{C}$ e imersão por $10 \mathrm{~min}$ em água a $10^{\circ} \mathrm{C}$, respectivamente), apresentaram menores faixas de escurecimento em comparação aos demais tratamentos (Figura 3). Ao final do experimento, no décimo dia (+3 dias de comercialização simulada a $20^{\circ} \mathrm{C}$ ), a percentagem de escurecimento de todos os tratamentos aumentou, sendo que o tratamento controle apresentou percentagens de escurecimento mais altos em comparação aos demais tratamentos (Figura 3).

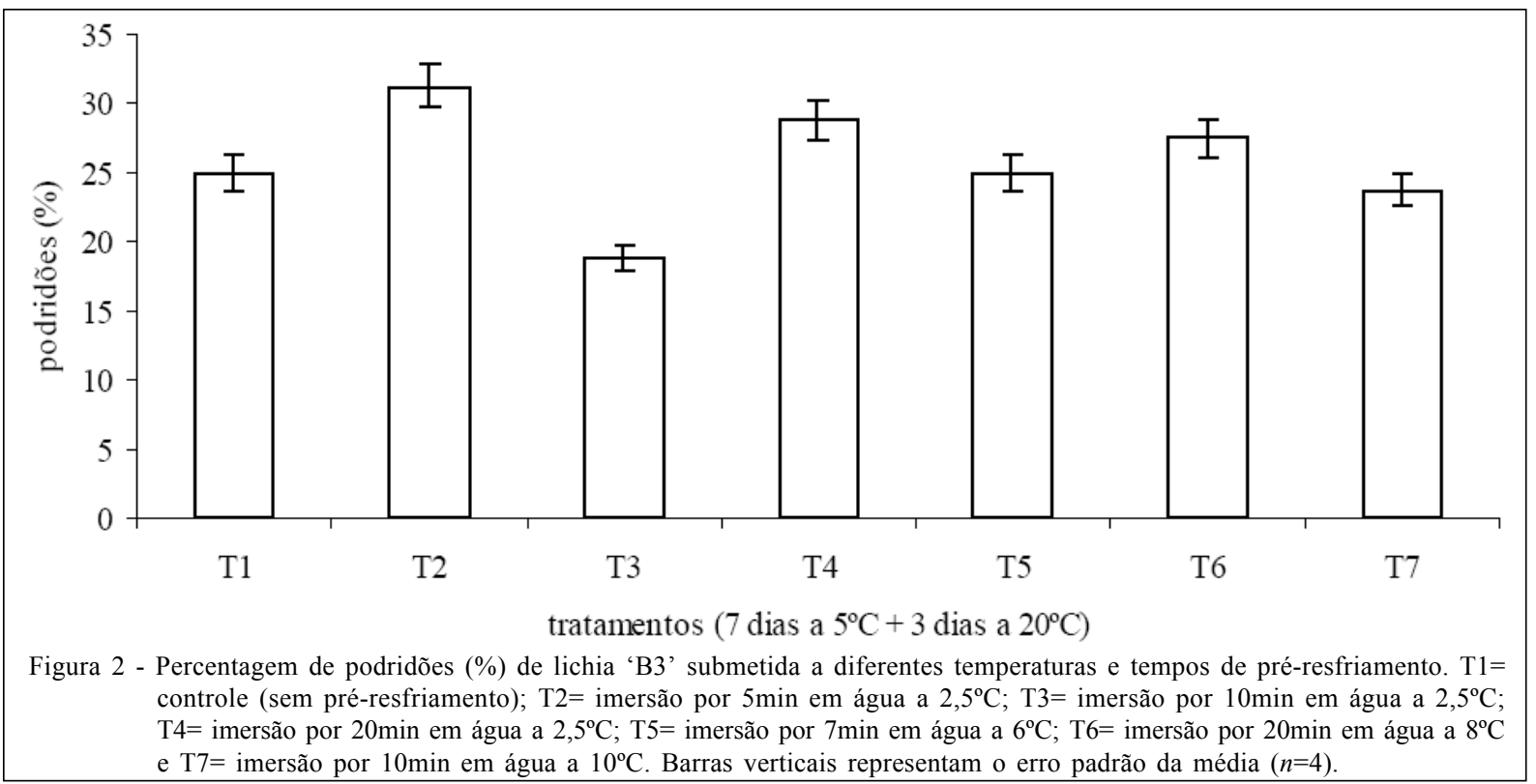

Ciência Rural, v.39, n.8, nov, 2009. 


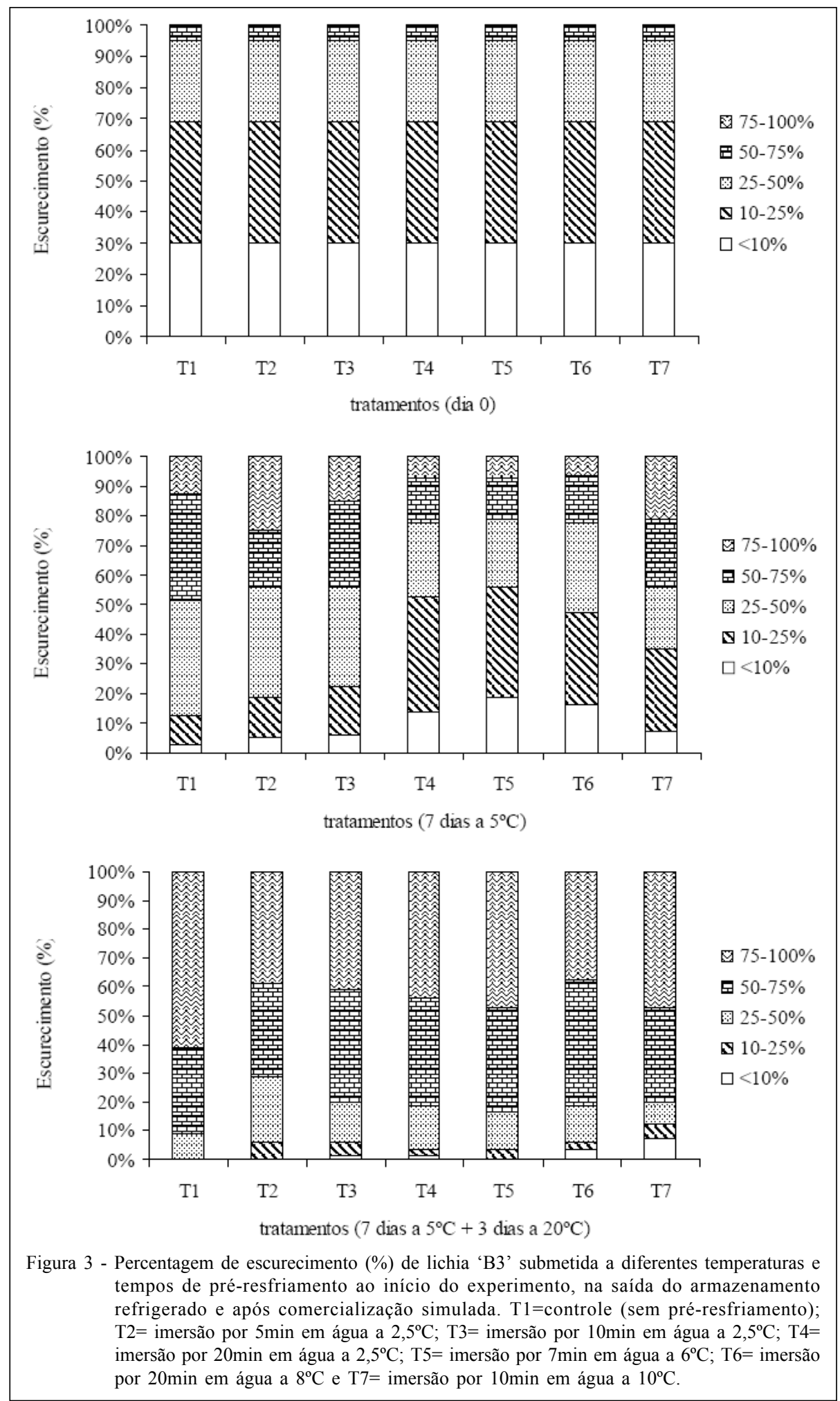

Analisando os resultados da luminosidade $\left(\mathrm{L}^{*}\right)$, foi verificado que o tratamento controle (sem préresfriamento) apresentou valores significativamente inferiores no sétimo e no décimo dia de experimentação, em comparação aos demais tratamentos, o que nos indica que esse tratamento apresentou um escurecimento no pericarpo do fruto de forma mais acelerada (Figura 4). Os valores de $a$ indicam dois 


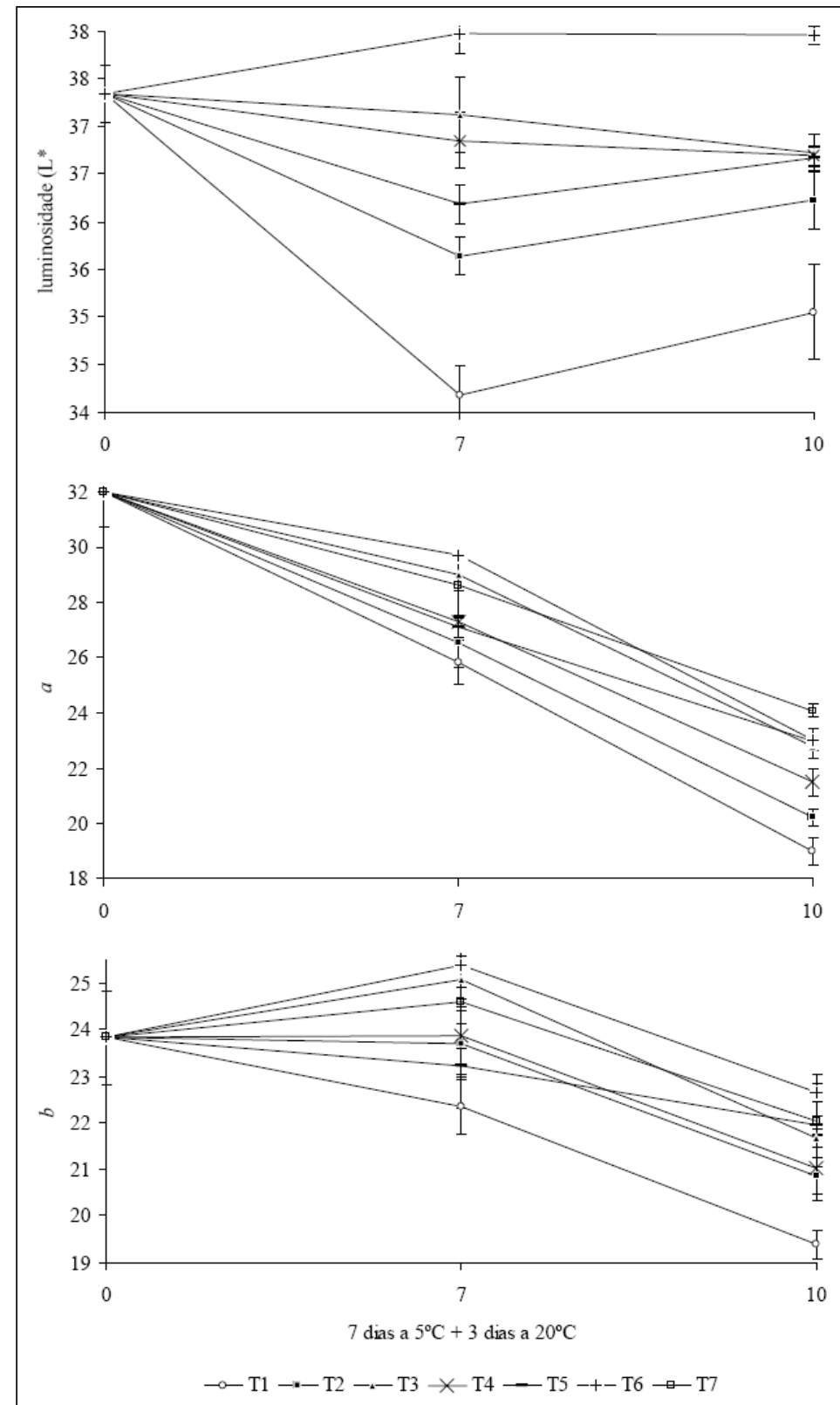

Figura 4 - Luminosidade ( $\left.\mathrm{L}^{*}\right), a$ e $b$ de lichia 'B3' submetida a diferentes temperaturas e tempos de pré-resfriamento. $\mathrm{T} 1=$ controle $(\mathrm{sem}$ pré-resfriamento); $\mathrm{T} 2=$ imersão por $5 \mathrm{~min}$ em água a $2,5^{\circ} \mathrm{C} ; \mathrm{T} 3=$ imersão por $10 \mathrm{~min}$ em água a $2,5^{\circ} \mathrm{C} ; \mathrm{T} 4=$ imersão por $20 \mathrm{~min}$ em água a $2,5^{\circ} \mathrm{C}$; T5 $=$ imersão por $7 \mathrm{~min}$ em água a $6^{\circ} \mathrm{C} ; \mathrm{T} 6=$ imersão por $20 \mathrm{~min}$ em água a $8^{\circ} \mathrm{C}$ e $\mathrm{T} 7=$ imersão por $10 \mathrm{~min}$ em água a $10^{\circ} \mathrm{C}$. Barras verticais representam o erro padrão da média $(n=4)$.

extremos de cor, vermelho e verde, sendo os valores mais altos e positivos mais próximos à cor vermelha, $\mathrm{e}$ os valores contrários ficam mais próximos de verde. $\mathrm{Na}$ figura 4, apresentam-se os resultados dessa variável resposta nos frutos submetidos aos diferentes tratamentos, sendo que, de maneira geral, observa-se um decréscimo desses valores, com o avanço dos dias de armazenamento e posterior período de simulação da fase de comercialização. Entretanto, os frutos do tratamento controle apresentaram os menores valores de $a$ no sétimo e no décimo dia de avaliação. $\mathrm{O}$ tratamento 7 , relativo à imersão dos frutos por 10 minutos em água a $10^{\circ} \mathrm{C}$, apresentou o maior valor de $a$ ao final do experimento. Os valores de $b$ são

Ciência Rural, v.39, n.8, nov, 2009. 
apresentados também na figura 4 , onde se observa que os frutos do tratamento controle apresentaram, também, os menores valores de $b$ no sétimo e no décimo dia de avaliação do experimento. Esse parâmetro avalia a mudança da coloração dos frutos entre as cores amarela e azul.

MALGARIM et al. (2006), trabalhando com morangos cv. 'Camarosa' pré-resfriados com água, não encontraram diferenças estatísticas com relação à luminosidade ( $\left.\mathrm{L}^{*}\right)$ e um comportamento irregular quanto aos valores de $a$ e $b$.

\section{CONCLUSÕES}

O pré-resfriamento da lichia 'B3' com água às temperaturas e nos tempos de imersão testados auxilia na minimização do escurecimento do pericarpo, dos valores da luminosidade ( $\left.\mathrm{L}^{*}\right)$ e de $a$ destes frutos; entretanto, favorece o surgimento de altos índices de podridões.

\section{AGRADECIMENTOS}

À Fundação de Amparo à Pesquisa do Estado de São Paulo (FAPESP), pela bolsa de estudo ao nível de Doutorado do primeiro autor (Processo: 04/15153-8), e à equipe do Postharvest Laboratory, do DPI \& F, Austrália, pelo apoio prestado no presente trabalho.

\section{REFERÊNCIAS}

BRACKMANN, A. et al. Pré-resfriamento e tratamento químico pós-colheita de maças cvs. 'Golden Delicius' e 'Fuji'. Ciência Rural, v.26, p.185-189, 1996. Disponível em: <http:// dx.doi.org/10.1590/S0103-84781996000200003>. Acesso em: 15 jul. 2009 . doi: 10.1590/S0103-84781996000200003.

CHITARRA, M.I.; CHITARRA, A.B. Pós-colheita de frutos e hortaliças: fisiologia e manuseio. Lavras: ESAL/FAEPE, 2005. 535p.
CORTEZ, L.A.B. et al. Resfriamento de frutas e hortaliças. Brasília: Embrapa Informação Tecnológica, 2002. 428p.

HOLCROFT, D.M.; MITCHAM, E.J. Postharvest physiology and handling of litchi (Litchi chinensis Sonn.). Postharvest Biology and Technology, v.9, p.265-281, 1996. Disponível em: <http://dx.doi.org/10.1016/S0925-5214(96)00037-3>. Acesso em: 29 abr. 2009. doi:10.1016/S0925-5214(96)00037-3.

JIANG, Y.M. et al. Postharvest characteristics and handling of litchi fruit - an overview. Australian Journal of Experimental Agriculture, v.46, p.1541-1556, 2006. Disponível em: <http://www.publish.csiro.au/paper/EA05108>. Acesso em: 29 abr. 2009. doi: 10.1071/EA05108.

KLUCH, H.D.W. et al. Efeito do pré-resfriamento e condições de armazenamento sobre a qualidade físico-química e lanosidade de pêssegos cv. Chiripá. Revista Brasileira de Agrociência, v.9, p.269-272, 2003

MALGARIM, M.B. et al. Sistemas e condições de colheita e armazenamento na qualidade de morangos cv. Camarosa. Revista Brasileira de Fruticultura, v.28, p.185-189, 2006. Disponível em: <http://dx.doi.org/10.1590/S0100-29452006000200007>. Acesso em: 15 jul. 2009. doi: 10.1590/S010029452006000200007.

MENZEL, C.M.; WAITE, G.K. Litchi and Longan: botany, production and uses. UK: CABI, 2005. 305p.

SAAVEDRA DEL AGUILA, J. Conservação pós-colheita de lichia (Litchi chinensis Sonn.). 2009. 162f. Tese (Doutorado em Fitotecnia) - Escola Superior de Agricultura "Luiz de Queiroz", Universidade de São Paulo, SP.

SAS INSTITUTE. The SAS System for Windows - Release 8,02. Cary, NC, 1998. 329p.

SEIBERT, E. et al. Efeito do hidrorresfriamento na qualidade de pêssegos 'Chimarrita' e 'Chiripa'. Revista Brasileira de Fruticultura, v.29, p.333-338, 2007. Disponível em: <http:/ /dx.doi.org/10.1590/S0100-29452007000200028>. Acesso em: 15 jul. 2009 . doi: 10.1590/S0100-29452007000200028. 